\title{
Assessing the Outcomes of Community-University Engagement Networks in a Canadian Context
}

\author{
Crystal Tremblay, Robyn Spilker, Rhianna Nagel, Jennifer Claire Robinson, \\ Leslie Brown
}

\begin{abstract}
Inter-organizational networks are proliferating as a tool for communityuniversity engagement (CUE). Focusing on three Canadian inter-organizational networks that bring communities and universities together, Community Based Research Canada (CBRC), the Pacific Housing Research Network (PHRN) and the Indigenous Child Well-being Research Network, this paper identifies key criteria for assessing these networks' outcomes and highlights factors that contribute to these networks' challenges and successes. This work is part of a growing body of scholarship seeking to better understand the role and contribution of networks in society and more specifically how the outcomes of these engagements might benefit and enhance collaborative research partnerships between civil society and higher education institutions. The results illuminate lessons learned from each of these three networks and their members. These findings inform broader research into community-university engagement networks and illustrate how these types of engagements can help build a stronger knowledge democracy in Canada and elsewhere.
\end{abstract}

KEYWORDS networks, community engagement, higher education, knowledge democracy, outcomes

There is currently a strong global trend to unite civil society, higher education institutions and networks in common efforts to "co-create knowledge, mobilize it to inform practice and policy, and enhance the social, economic and environmental conditions of people, communities, nations and the world" (Tremblay et al., 2017, p. 391). There is also a growing body of scholarship and interest in the epistemological revolution and movement towards a knowledge democracy, a relatively recent concept described by Tandon et al. (2016) as the "recognition of ecologies of knowledge and cognitive justice such as organic, spiritual and land-based systems, frameworks arising from our social movements, and the knowledge of the marginalised or excluded everywhere" (p.3). Among other key values as described by Tandon et al. (2016), knowledge democracy is about taking action in social movements and elsewhere to deepen democracy; it's about open access for the sharing of knowledge and intentionally linking values of justice, fairness, and action to the process of creating and using knowledge. Our work presented here is largely informed by a theoretical framing of these ideals, and those 
situated in community-based research. Our thinking is also guided by the premise that higher education institutions have an ethical obligation to contribute to the common good, and that community engaged scholarship can provide an important conceptual umbrella for organizing that civic mission (Cuthill, 2012).

It is through this lens that we shed light on Community University Engagement (CUE) networks as spaces that bridge universities, governments, First Nations, civil society organizations, industry, and community representatives on an organizational level. On an individual level, these networks connect researchers, policy analysts, and citizens as well as leaders from First Nations, civil society, businesses, and governments with the hope that dialogue among diverse stakeholders will create mutual understanding, innovative ideas, and stronger linkages between research, practice, and policy. Such complex open systems can be unpredictable as they are richly interactive and dynamic and involve many citizens and stakeholders. A lack of resources and internal struggles between members can make it harder for networks to be effective. Attempts to influence one part of the system can have far-reaching repercussions. These networks bring together organizations and individuals with diverse knowledge of the systems in question, allowing for a more holistic collective understanding for issues. Thus, networks may be able to influence various levers for change within these systems to collectively address contemporary; however, the nature of these complex systems makes it difficult to disentangle the networks' outcomes from other influences on the system. Zornes et al. (2015) highlight the obstacles specific to networks for establishing evaluation criteria and measures related to community-based impacts and outcomes beyond 'quantitative' measures.

This paper focuses on three inter-organizational networks that bring different communities and universities together to assess the outcomes of these networks, focusing on the overarching research question "how and in which ways do CUE networks enable equitable and accessible knowledge co-creation between higher education and civil society?" The three participating networks are Community Based Research Canada (CBRC), the Pacific Housing Research Network (PHRN), and the Indigenous Child Well-being Research Network. The findings in this paper are based on document analysis, literature review, and in-depth interviews with members of each of the networks. This paper begins by defining networks more broadly, particularly related to community university engagement, cross-sector collaboration, and social change. Following this is a discussion of the key benefits of networks, and factors found to influence network success, as identified by our participants. A methodology for assessing the outcomes of these three networks and a description of the networks follows. The primary aim of this research is to inform the three participating networks and their members of the beneficial outcomes of these engagements and to provide further insight into the obstacles and successes of CUE networks.

\section{Unpacking CUE Networks}

Malinsky \& Lubelsky (2014) define networks as open systems of "relatively autonomous actors that are working in concert to achieve shared goals or pursue individual goals within a shared system" (p. 8). What a network can achieve depends in part on their members' skills, 
knowledge, access to resources, and influence in their community or organization (Head, 2008). Membership in these networks can be small or large, heterogeneous or homogenous, comprised of individuals or organizations, from any sector or field, and are localized, national or international in scope (Head, 2008; Malinsky \& Lubelsky, 2014). Researchers have observed that networks generally have internal aims, such as "information exchange and capacity building for network members, and external aims such as policy change, service delivery, and planning” (Head, 2008, p. 738). Plastrik \& Taylor (2006) expand on this concept by identifying three common network goals and relating them to stages of network development. First, all networks foster connectivity by linking people and organizations. Second, many networks build on connectivity to create alignment through developing shared values and a collective sense of identity. Third, some networks build on connectivity and alignment to produce external outputs of varying types. The array of possible outputs includes producing goods and services, influencing policy, promoting promising practices, mobilizing citizens, and developing innovative solutions to social and economic issues (Plastrik \& Taylor, 2006).

The prevailing view of networks is that many organizations with shared aims will be more effective working together than if they compete or function separately (Provan \& Milward, 2001). There is an advantage to working collaboratively as multiple organizations can often harness a wider range of knowledge and resources to achieve a coordinated goal (Proven et al., 2005, p. 603). Pressure to collaborate is especially strong within the public and third sector due to resource scarcity, the complexity of problems, and the need for horizontal coordination between organizations that have developed specific specializations (Provan \& Milward, 2001). Anderson et al. (2010) argue that addressing complex problems requires distributed leadership across sectors, networked efforts, and citizen engagement as action. Furthermore, for networks to address complex social, economic, and environmental problems, they need relevant knowledge and skills.

Community-university engagement networks may be especially useful because they can mobilize the knowledge, skills, and assets of both universities and communities. The most recent World Report in Higher Education makes a strong case in support of building knowledge networks. Because "[t]he complexity, dynamism and global nature of our current context requires a huge amount of knowledge and, at the same time, social dialogue" (Vilalta et al., 2017, p.405), it is no longer possible, argues Vilalta et al., (2017), for an institution or organization (whether a government, university, company or any other) to act with full autonomy and resolve questions that are in themselves complex and interdependent.

Such partnerships apply rigorous research approaches and value community knowledge that is place-based and context specific to democratically find solutions to contemporary challenges (Popp et al., 2013). As Escrigas et al. (2014) explain (or emphasize), inter-organizational networks are proliferating as a tool for CUE (see also Hall et al., 2013; Hall et. al, 2015). These networks bring community-based and university-based representatives together to work towards a common purpose, often to benefit communities and develop solutions to social, economic and ecological problems (Popp et al., 2013). Community-based representatives can include individuals from non-profits, governments, First Nations, industries or community 
groups. Meanwhile, university-based representatives can include researchers, administrators, faculty members, staff members, and students. Though research on CUE networks is a developing field, CUE networks fall within the broader category of cross-sector and social change networks that seek to benefit citizens and communities.

\section{Assessing the Outcomes of CUE Networks}

Considering their proliferation and their foci on such complex problems, it is both necessary and difficult to explore how CUE networks are benefiting their members, their organizations, and their communities. In considering networks, researchers tend to evaluate whether networks have positive outcomes that support effective processes and desired results for the network (Provan et al., 2007). Bryson et al. (2006) state that collaborations can have three levels of positive impacts: "First-order impacts are those that are immediately discernable, directly resulting from collaboration processes" (p. 51). Examples include the development of innovative strategies, social capital, and information sharing. Second-order impacts tend to occur when collaborative processes have gained momentum: "these might include new partnerships, coordination and joint action, joint learning that extends beyond the collaborative, implementation of agreements, changes in practices, and changes in perceptions" (Bryson et al., 2006, p. 51). Then third-order impacts are generally long-term; they can include "new collaborations, more co-evolution and less destructive conflict among partners; results on the ground, such as the adaptation of services, resources, cities, and regions; new institutions; new norms and social heuristics for addressing public problems; and new modes of discourse" (Bryson et al., 2006, p. 51). Given that networks have a diverse range of outcomes, some are easier to measure than others. As stated by MacPherson \& Toye (2011), "the longer-term impacts $[\ldots]$ are contingent on the individual and organizational members of the network and how the focus of the network is being addressed or impacted by other forces" (p. 61). The evaluation of network outcomes and effectiveness is often steeped in evaluating network processes, dynamics, and incremental steps.

Plastrik \& Taylor (2006) describe an evaluation approach that aims to measure connectivity, overall health, and results. Connectivity focuses on how effectively information and resources are flowing through a network and how these flows are shaped by network structure. Network health focuses on the presence or absence of internal conditions required to achieve long-term goals. While each network will come up with different indicators for this, common ones include adequate resources, diversity, growth, and active participation by members. Network results are difficult to assess, but Plastrik \& Taylor (2006) suggest identifying intermediate indicators of incremental changes that demonstrate the network is moving towards its goal. They argue that evaluation should start with an understanding of what essential role networking plays in achieving impact. Taylor et al., (2015) recently published an evaluation assessment rubric considering network stages of evolution and network conditions (such as connectivity and leadership). This incorporation of network stage into the evaluation allows for developing a more case-specific understanding of a given network.

Provan \& Milward (2001) present an output-focused evaluation framework for 
community-based networks, especially those that deliver health and human services. They consider community-level, network-level, and organization/participant-level outputs, and the stakeholders associated with each level. As Provan \& Milward (2001) state, "at the broadest level of analysis, community-based networks must be judged by the contribution they make to the communities they are trying to serve" (p. 416). For instance, community-level contributions could be measured by the incidence of a problem the network addresses, the mobilization of community assets, or the growth of social capital. Then on the network-level, evaluation focuses on whether the network is a viable collaboration between organizations. Outputs at the network-level can include network growth, relationship building, common understanding of goals, and coordination of activities. Finally, organization and individual members are motivated to participate in their network through the promise of value creation for themselves and their organizations. Organization and participant level outputs include accessing information, acquiring more resources, reducing the cost of transactions between organizations, and gaining legitimacy through affiliation.

Throughout the literature on evaluating cross-sector and social change networks, there is an emphasis on customizing evaluation to suit a network's needs. This often requires determining what outcomes a network's members, community, and stakeholders are most interested in observing. Factors that influence network outcomes can provide insight into network impacts. While networks and their evaluation strategies are diverse, researchers and practitioners have identified some common factors that influence networks' effectiveness and ability to create impact. These factors are access to resources, alignment and planning, communication, bridging and linking, trust and conflict resolution, learning, leadership, and governance. The results of this research have been organized around these factors.

\section{Methodology for Assessing the Outcomes of CUE Networks}

The three networks in this study were chosen for the diversity in their purpose, membership, represented sectors, geographical scope, size, and for their association with the Institute for Studies and Innovation in Community-University-Engagement (ISICUE), a former research centre at the University of Victoria (UVic) dedicated to bridging the university with community organizations. ISICUE's involvement in these networks ranged from providing administrative support, shared resources, staff, and leadership, to serving as an affiliated research organization. Interviews were held with three members of each of the three networks who chose to participate in this study. As this research was designed to be exploratory, these interviews were semi-structured in form to allow interviewer and interviewee to have more of a collaborative conversation with both parties learning more about CUE networks, their functioning, and their key outcomes. Interview questions related to the interviewees' personal experiences of participating in the network; to the internal form, function and processes of the network; and to the external relations and influences of the network. Interview transcriptions were analyzed through an iterative process of thematic coding based on the literature and the emerging elements from each interview. 


\section{Pacific Housing Research Network (PHRN)}

The PHRN network officially launched in early 2012 "to facilitate multi- sectoral housing research activities across $\mathrm{BC}$ and foster dialogue and collaboration among housing researchers and stakeholders to encourage the effective application of research results to housing solutions" (PHRN, 2013 - Winter Newsletter). Membership to PHRN is free and open to all and implies subscription to PHRN E-News. This provincial network is co-chaired by researchers from the University of Victoria and one from the University of British Columbia. The steering committee consists of representatives from Canada Mortgage and Housing Corporation (CMHC), MITACS (funder), the Housing Policy Branch of the Government of BC, BC Housing, UBC, UVic, and the BC Nonprofit Housing Association (BCNPHA). PHRN has one hired staff member as the network coordinator. BC Housing and CMHC provide funding, with major in-kind support from ISICUE and UVic and significant in-kind support from other Steering Committee partner organizations. PHRN holds a yearly housing symposium, which brings together scholars, practitioners, and policy makers. The network publishes two to three newsletters a year; hosts a website with network news (http://phrnbc. $\mathrm{com} /$ ), housing related resources and symposium information; sends out monthly to bimonthly e-news to subscribers; supports students through work-study positions, awards and networking opportunities; and promotes events, opportunities and resources through Twitter.

\section{The Indigenous Child Well-being Research Network (ICWRN)}

The Indigenous Child Well-being Research Network brings together a variety of Indigenous peoples representing both on/off reserve; status/non-status; Métis, Inuit, and First Nations in response "to an urgent need for Indigenous approaches to research topics that are grounded in the experiences and voices of Indigenous children, youth, families and communities" (ICWRN, 2013). The network began in 2009 as the Indigenous Child Welfare Research Network (ICWRN) with the vision that "one day our children will laugh and play freely in their communities with their families" (ICWRN, 2010, p. 3). Membership to ICWRN is free, open to all and provides access to resources, literature and people who specialize in Indigenous Research (ICWRN, 2013). Staffing fluctuates based on funding and ICWRN currently has one hired staff member as the administrative assistant. Funding is primarily grant-based through supporters such as Vancity and the Vancouver Foundation, with core support from the Faculty of Human and Social Development at UVic. ICWRN also raises funds through service fees for research and engagement projects. The Executive Committee consists of three researchers from UVic and one from the University of British Columbia (UBC). The Steering Committee is composed of mainly Indigenous professors from UVic, UBC, and Australia, with four serving as executive members of the network (ICWRN, 2013). ICWRN also has an Advisory Committee, with representation from various territories in order to promote, advise and liaise to community, agencies and institutes (ICWRN, 2013). The network hosts a website which showcases ICWRN-led research, resources, publications, presentations and opportunities. ${ }^{1}$

\footnotetext{
${ }^{1}$ ICWRN website: http://icwrn.uvic.ca/
} 
ICWRN facilitates training with Indigenous communities and are dedicated to highlighting and using Indigenous methodologies. Through the network's projects, significant works have been published on methodologies and specific topics of interest.

\section{Community Based Research Canada (CBRC)}

Community-based Research Canada (CBRC) began in 2008 as the Pan-Canadian Coalition for Community Based Research. As of 2013, CBRC's vision has evolved to become a national champion and facilitator of community-based research (CBR) in the broader context of community-campus engagement through its network of postsecondary institutions and community partners. CBRC membership is open to all and a paid membership strategy began in 2012 to sustain core administrative funding for the network; fees range depending on the type and size of the member organization. The network hosts a website which profiles its members, provides opportunities for networking, and shares resources and network news. CBRC's Engaged Practice Learning Exchange (EPLE) supports on-line networking opportunities and facilitates face-to-face workshops on topics of interest, as identified in CBRC's member survey in 2008. CBRC also supports CUExpo, a bi-annual conference that "allows community members, universities, colleges, government, and nonprofit organizations to work together to create an innovative learning environment where research, knowledge, and relationships can be shared and cultivated" (CBRC website). CBRC is governed by a steering committee of CBR leaders from universities and civil society across Canada, which is supported by a secretariat housed at the Centre for Community Based Research (CCBR) in Kitchener, Ontario.

\section{Results from Participating Networks: Key Outcomes}

Through thematic analysis of interviews and CUE related literature, the following factors affecting network access stood out as resonating with the networks' approach to understanding their outcomes: access to resources, alignment and planning, communication, bridging and linking, trust and conflict resolution, learning, leadership, and governance. This could be the result of the generally early stage of the network and/or the limited resources available to formally evaluate efforts or undertake in-depth network assessment. Thus, many of the interviewees did not directly nor concretely portray specific network outcomes, hence the value of this study in starting this conversation. The following is an overview of network interviewee responses in relation to these factors.

\section{Access to Resources}

Both human and financial resources are required to perform collaborative work (FosterFisherman, 2001; Plastrik \& Taylor, 2006; Provan et al., 2007). All those interviewed from the three networks identified access to resources as an underlying success factor for networks to achieve their desired outcomes. Generally, it was found that as a network, members can access resources and tools that they could not access without the multi-stakeholder network and that financial resources are primarily dedicated to buying time. In-kind human resources 
offer the bulk of leadership to each of the three networks and this is commonly the case in CUE networks (McPherson \& Toye, 2011). While dedication, passion, and position are vital to the possible impacts of the network, there is danger in individual burnout, particularly if capacity is weak within the organization for succession planning. In this light, every interviewee and many of the reviewed documents outline the importance of a paid coordinator role. In fact, financial resources were primarily deemed necessary to maintain the coordinator role and their associated tasks. Each participating network observed that through supporting the secretariat, and/or maintaining a paid coordinator position, they could see and fill gaps, and increase capacity to move beyond network maintenance to network growth, formalization and innovation.

A strength in CUE networks in relation to access to resources is the ability to leverage the attributes of community and university partners for acquiring funds. Community organization partners were identified as providing community contacts, contextual understanding, and support letters. Similarly, researchers and staff in the institutions were identified as providing connections, time, and access and ability to write research grants. CUE networks can access research funds, which have the capacity to "create opportunities for engagement at the community level" (Interviewee). Furthermore, individual and organizational funding opportunities are shared throughout the networks. However, due to reduced and constrictive funding, network members are, as one interviewee noted:

Absolutely burnt out and overworked ...[...]... whether we have funding makes all the difference so if you don't have a large amount of core funding you are spending all your time applying for special project funding... without the core funding we are limited in our capacity to follow up, develop new partnerships, have a proper functioning listserv and the networking piece is often the first to go.

Considering the importance given to 'networking' in 'networks,' the impacts of this funding challenge is significant. Institutional support for researchers enables network activities to continue even when their financial resources are not acquired; the researchers themselves, and institutional work-study and student internship type positions can provide a strong motor for the network while financial and volunteer resources are low. However, when accessing funds for research that are administered through university institutions, the institution uses a percentage to support administration. Both community and university partners voiced frustration in this process. The downfall of research funds, stated one of the interviewees, is in "how the funding was handled for the project. Some of it if it went through the regular research funding stream of the university, we lost $\$ 5,000$ every time."

Each network also highlighted the need for a clear identity to acquire funds and support, and yet, requiring funds to appropriately define their identity. Given the complex nature of CUE networks and the complex issues that they are aiming to address, this conundrum can be a burden for network members and leaders and can create tension. Apart from funders increasingly asking for clearly defined grantees, a crystallized identity can be helpful 
in avoiding opportunistic funding sources that can distract network members from the network's purpose.

\section{Alignment and Planning}

Much of the literature identified network-level goal clarity and agreement on project objectives as desirable, though, not always essential for networks to function effectively (Bryson et al., 2006; Foster-Fisherman et al., 2001; Head, 2008; Provan \& Kenis, 2008). However, those interviewed for this research strongly suggest that it is easier to understand the impacts and influences of the network when the question of a network for what? is answered. A clearly defined identity and strategic plan are important for responding to that question. Without these, the value of the network cannot be portrayed to new members, funders, and the broader public. As one interviewee stated, having a "clear identity is what moves things along."

Many interviewees found that part of creating a strong identity is being more robust, and part of it is the visibility and credibility in the broader community. The process and product of a collaboratively developed strategic plan is what support network alignment between individual, organizational, and network level goals and visions, according to several interviewees. "The plan makes things much more real, a couple of years ago it was an idea. Now it's an idea with a good plan and people working towards it and actions coming out of it," said one interviewee. Another stated that "the plan is great and moves us along" because it clarifies the mission and goals and builds necessary structures for achieving those, without over-bureaucratizing. One participant said that what "makes the governance group work...is that they are pretty clear about their shared mission." In determining priorities, the strategic plan is fundamental for clarifying the details of the network's work; practical objectives assist the network in aligning with its vision.

One network used a network member survey as a tool to develop the strategic plan and then wrote the plan collaboratively. Apart from the value of clarifying work, the process of collaboratively developing the strategic plan was identified as having the impact of growing capacity and connections within the network. One participant said that their network is in the early days and is thus still defining the "general direction of where and how and why we do the things we do...it would be false to say 'here are the great things that we get from the network.' It's an early network, we are building it now.” Developing network identity requires significant time and internal and external relationship building.

In the development and solidification of the network identity, the greatest impacts, both intended and secondary, seem to occur when there is alignment between individual, organizational, and network level visions and goals. It was observed that when this alignment occurs, involvement in the network contributes to solidifying work at members' home organizations and vice versa. This reciprocal relationship then fosters the growth of the societal movement that the network is aiming to contribute to. One participant said, "there's a movement, there's a network, and there's an organization, and how do you keep the three going at the same time?" Two impacts associated with alignment and planning that were identified by interviewees are 1) developing a more robust network, and 2) creating more 
visibility and credibility in the broader community, both of which feed back into alignment and planning. Furthermore, there is emphasis on the importance of network identity, vision, and goals aligning with network activities. With this clarity, internal and external network communications are more readily facilitated and meaningful.

\section{Communications}

Communication was identified in the interviews as being the role of the network. With this important designation assigned, network impacts come to light when looking at the questions of who is communicating what, to whom, and how. While this differs with each network, a common factor of success in communications was using the right language to clearly convey the network's message and activities, while still attracting interest from members (to-be and active), funders, and other stakeholders. The participating networks were either provincial or nation-wide in their scope. Thus, each faced geographical barriers to communications. Furthermore, the active members of each network are very busy, with tight schedules, and at times, restrictive organizational policies around communications.

The purpose of network communications varied slightly between the networks, but generally provided information about the network to members and the public, built momentum around an issue or activity, created internal and external connections, encouraged new membership, shared research and other resources within the network and developed funding applications. Through network communication modes, members could communicate opportunities, passions, resources, and knowledge with each other, with network partners and funders, and with the public. Such communication provides the opportunity for policy makers to accept (or continue?) research, for movement building, for developing new audiences for research and community work, and for students and community members to participate in research. The identified modes of communication used in the networks are the following: Skype, website, email, telephone, conferences/ symposiums, electronic and hardcopy newsletters, annual faceto-face meetings, and Twitter (see Table 1 below).

Table 1. Identified modes of communication used in the networks.

\begin{tabular}{|l|l|l|}
\hline $\begin{array}{l}\text { Mode of } \\
\text { Communication }\end{array}$ & Benefits & Challenges \\
\hline Skype & $\begin{array}{l}\text { Facilitate communication } \\
\text { between geographically distant } \\
\text { members; easily used for } \\
\text { trainings and meetings }\end{array}$ & $\begin{array}{l}\text { Technology sometimes } \\
\text { problematic }\end{array}$ \\
\hline
\end{tabular}




\begin{tabular}{|c|c|c|}
\hline Website & $\begin{array}{l}\text { Maintain transparency; } \\
\text { showcase network vision, } \\
\text { activities and members; share } \\
\text { resources and learnings from } \\
\text { face-to-face interactions; "A lot } \\
\text { of research communications, } \\
\text { a little more network } \\
\text { communications" (Interviewee) }\end{array}$ & $\begin{array}{l}\text { "Place for information not so } \\
\text { much communication, at least } \\
\text { not two-way" (Interviewee) Lost } \\
\text { information when changing } \\
\text { platforms. One network lost } \\
\text { significant documentation of } \\
\text { presentations, reports and } \\
\text { program evaluation when } \\
\text { switching platforms and } \\
\text { therefore lost some of the } \\
\text { transparency that they had } \\
\text { worked so hard to achieve. }\end{array}$ \\
\hline Telephone & $\begin{array}{l}\text { Provides more clarity than } \\
\text { emails }\end{array}$ & \\
\hline Email & $\begin{array}{l}\text { "Email was key source for } \\
\text { all kind of information" } \\
\text { (Interviewee) }\end{array}$ & $\begin{array}{l}\text { Can be ambiguous; difficult to } \\
\text { read tone }\end{array}$ \\
\hline $\begin{array}{l}\text { Conferences/ } \\
\text { symposiums }\end{array}$ & $\begin{array}{l}\text { Creating face-to-face } \\
\text { connections between multiple } \\
\text { members and diverse } \\
\text { partners; energizer; "facilitate } \\
\text { and foster...inter-person } \\
\text { communication" (Interviewee) }\end{array}$ & $\begin{array}{l}\text { Geographically distant members } \\
\text { may not be able to attend; cost; } \\
\text { human resources related to } \\
\text { planning }\end{array}$ \\
\hline Hardcopy newsletter & Ready material for meetings & Cost \\
\hline Electronic newsletter & $\begin{array}{l}\text { "Pushing out" information } \\
\text { to broad audience and } \\
\text { through member's individual } \\
\text { networks; easy to disseminate; } \\
\text { can use “...e-news analytics } \\
\text { to talk about some impact } \\
\text { quantitatively" (Interviewee) }\end{array}$ & \\
\hline $\begin{array}{l}\text { Printed informational } \\
\text { brochure }\end{array}$ & $\begin{array}{l}\text { Ready material with general } \\
\text { network information }\end{array}$ & $\begin{array}{l}\text { Cost, especially when reprinting } \\
\text { is required for updated } \\
\text { information }\end{array}$ \\
\hline $\begin{array}{l}\text { Annual face-to-face } \\
\text { meeting }\end{array}$ & Getting on the same page & $\begin{array}{l}\text { Cost; human resources related to } \\
\text { planning }\end{array}$ \\
\hline
\end{tabular}




\begin{tabular}{|l|l|l|}
\hline Twitter & $\begin{array}{l}\text { "Pushing out" information to } \\
\text { broad audience and through } \\
\text { member's individual networks; } \\
\text { can use "twitter [...] analytics } \\
\text { to talk about some impact } \\
\text { quantitatively" (Interviewee) }\end{array}$ & $\begin{array}{l}\text { Maintaining and updating } \\
\text { account requires significant } \\
\text { human resources }\end{array}$ \\
\hline
\end{tabular}

It can be difficult to establish commonly agreed-upon language that resonates with the network's broader public and respects the political climate of members. "The broader your reach is, the more accessible your communications need to be," stated one interviewee. Without the appropriate language, it is difficult to cultivate the internal and external bridges and links that ultimately increase a network's influence. For the most part, it was observed that communication is streamlined through the role of a Project Coordinator or Project Manager, with side conversations occurring between members and with funders. One of the interviewees stated that members were originally communicating with multiple people, but now communication is mostly "streamlined from one person, which is easier because you know who to contact." In this sense, the coordinator acts as a repository and conduit of information.

\section{Bridging and Linking}

Creating a shared understanding of issues and collective support for network goals requires working across organizations, sectors, and social positions. Bridging stakeholders with diverse viewpoints can be essential for achieving such alignment (Head, 2008). Additionally, bridging to a wide range of organizations and sectors can increase a network's access to funding, information, people and other resources, ultimately increasing their influence (FosterFisherman et al., 2001). Each of the networks is committing significant time, energy, and financial resources to creating shared understanding and collective support for network goals through bridging a wide array of organizations, sectors, and social positions. While the individuals within the network are producing the research, the network serves to create the linkages.

While each network specializes in a unique sector, they are often presented as hubs, focusing on "ways in which you build more rigour or robustness [...] and how [to] best draw upon the strengths represented" in the field (Interviewee). Another interviewee stated that the network demonstrates great "sectoral involvement and reach" and that there is "great representation and a high level of collaboration." Another interviewee said, "if you can't do it alone, do it together right." Regarding the impact of working together within the network, one interviewee noted that "fostering contribution and participation, I think, certainly allows for connections to be made between people." Further, developing dialogue with many different actors and between sectors solidifies connections. Conferences, symposiums, and face-to-face interaction were identified as the preferred means of initiating this dialogue and working relationship. 
When asked how their networks were impacting their field and how being part of the network impacts their work, interviewees focused significantly on how the networks "support space to build a movement" and reduce fragmentation. Some interviewees observed that they and others valued their individual and organizational level work more through sharing it and grouping it with other network members' work. As one interviewee articulated, “it is helpful to know other people in the network and be able to get things done. So, the collegial support of linking national and international voice I think that's had an influence locally." The same interviewee described an external expectation for networked sectors and a consequent credibility challenge related to sharing a network identity with peers in the field. As network members and/or partners, funders are also developing dialogue around funding priorities and processes with networks where historically the relationship was primarily based on applications and responses.

One impact of CUE networks in communities is a shift in community-university relations. "Over time they have developed the rapport and relationship with communities," stated one interviewee. This creates common ground for community and researchers and makes "research accessible and practical for the community based world." One of the networks focuses a significant amount of time on supporting communities through capacity building and deconstructing power structures around research. In this case, interviewees shared significant personal impact stories related to their work in community. For example, one interviewee expressed the following:

So much of our work is decolonial re-centering, re-storying what research is. And it's a decolonization process, and a healing process. And to see it, and to be with Elders who have been told you know, your language doesn't matter, your knowledge doesn't matter... To have spent two days praying together and drumming and honoring the stories and developing a new vision, that is the impact - like reclaiming research is the impact. To us that's tremendous.

Further, the interviewee describes the significance of a decolonizing research process within her own work and that of being a bridge builder and translator with government:

On one hand communities weren't interested in doing their own research, I think in part because research had always been positioned as a colonial endeavor, coming from colonial institutions.... And then what was used to find and assess agencies, even if they were Aboriginal, was still coming from colonial research. So, it was kind of this perfect opening for Indigenous academics to step into and say can we work with community in partnership, following Indigenous ethics, following different protocols not this helicopter Euro-western appropriation model, and work with communities to look at their own practices, knowledge and then translate that back. And then on the other prong other end of the spectrum; work with government and policy makers for them to understand research evidence and evaluation and program design in a much broader way. So, kind of doing that translation bridging work. 
While these personal outcomes came from issue-specific work, the interviews and documents highlight a difference of opinion around whether it is appropriate to bridge and link around specific issues. Comments showing resistance to issue-based bridging included the following: the network needs to "support and create space, not create demands and create stands"; not issue-driven, but capacity and communications driven to encourage connection from more people, particularly those who are risk adverse (including funders); it is difficult to speak with one voice as a network due to political circumstances of those involved; broad framing of work "so that ... [...]... stakeholders can all take part in it, so it will be kind of general"; the network is not for talking about specific issues, but for building relationships and the network itself. Comments favouring issue-based bridging included the following: the idea is that the network can "address questions and issues that matter and make a difference on those issues in ways that we wouldn't otherwise be able to do" and "collaborate on the national level about funding and addressing big issues." It seems that the strategy that two of the networks have adopted in response to this tension is to meet the views in the middle and identify "overarching themes." Increasing network reach perhaps enables the growth of a movement that will, through its various actors, address more controversial issues.

\section{Trust and Conflict Resolution}

Collaborations require building trust over time, as members develop relationships, share information, make progress on goals, and demonstrate competency, good intentions and follow-through (Bryson et al., 2006; Foster-Fisherman et al., 2001; Head, 2008). Bryson et al. (2006) argue that conflict is common in cross-sector collaborations due to differing histories, organizational cultures, expectations, and aims; therefore, collaborations function more effectively when conflict is managed and power dynamics are negotiated. All interviewees from each of the networks identified significant trust within the networks and with network partners. This trust was related to intentions in that it was commonly portrayed that everyone is involved for the right reasons. Consequently, there is more patience for diversity of ideas and approaches. As one interviewee put it, "I can't talk about inclusiveness and transparency without talking about...the intentions of the people who come together. They respect each other's intentions. So, there is no nonsense...it's really wonderful." This trust was also related to credibility in that individuals give the network credibility and the network gives individuals credibility. This "good credibility piece in both directions," as one interviewee called it, is an interesting outcome of participating in CUE networks. The working relationships of the CUE networks provide an opportunity for trust to develop, which in turn supports committed working relationships.

\section{Learning}

Learning or continuous improvement orientation is another factor that can support networks to achieve beneficial outcomes (Head, 2008; Plastrik \& Taylor, 2006). Foster-Fisherman et al. (2001) characterize continuous improvement as the process of seeking feedback from internal and external sources, including monitoring systems and evaluations, then using the 
feedback to develop as an organization. Each of the participating networks evaluated specific activities in response to funders' metric criteria. Several interviewees said that these evaluations resonated only slightly with what the network and its members wanted to learn to move forward. Only one of the networks used a formal survey to support network improvements. They found that this evaluation was extremely useful for creating more alignment between individual, organizational and network goals and visions. However, the networks identified time for administering, participating in, and documenting network evaluations as the reason why formal network evaluation is not occurring. Informal evaluation, though perhaps not as impactful, is occurring within each of the networks.

\section{Leadership}

Leadership capabilities that benefit networks include the ability to be task oriented, mobilize assets and strengths, market strategic opportunities, and adapt to changing contexts (Bryson et al., 2006; Foster-Fisherman et al., 2001; Head, 2008). Bryson et al. (2006) point to the value of informal leadership throughout the network, as members' participation is often self-directed, actions are decentralized, and decision-making is shared. In addition, networks often rely on leaders that fill champion and sponsor roles. Sponsors use prestige, authority, and access to resources to sustain collaborations though they may not be involved in day-to-day work; meanwhile, champions use their energy, time and process skills to further the collaboration and lead day-to-day work (Bryson et al., 2006).

It was expressed in each of the interviews that leaders within the networks demonstrate real commitment to the network. One interviewee said that the strength of the network is in "the dogged determination of the individuals of the group...the sense of willingness and camaraderie... of the executive and steering committees." They added, "it is a huge strength to have people who have so much experience who actually believe in what they are doing.... Each can give something different and have different strengths in their experiences." It was also stated that "for nobody is it a paid job" and that "it's being done for the greater good and not your actual CV and that's where the commitment comes in. That is really impressive." Individual researchers were singled out as being instrumental in moving things forward by allowing the network access to their funds and connections. One interviewee stated that "everyone at the table is a leader in their sector or they wouldn't be there. They are leaders, they speak like leaders, they have expectations of leaders, and they bring constituencies to the table." Another stated that "the movers of the network are not only bringing their individual commitment and ability but they bring with them the knowledge, respect and connections that are the lifeblood for developing genuine university-community engagement." So individuals are using their networks to expand the network and increase visibility. However, it was also highlighted that "[a] good leader... is somebody who speaks the language of the academics and the language of the local community...If you don't speak the language you will be closed in your ivory tower."

While each of these networks has a community focus in their mission, the leaders at the universities and their administrative support were praised for being the key drivers in getting 
things going and having the ability "to make some shifts...not just through their network, but through their positions within the university they're able to influence policy and practice through the various committees that they might sit on whether that's in the government sector or the private sector." A lack of community leaders at the network tables was identified; one interviewee described leadership as "pretty university-centric." When asked why this was so, several interviewees responded that the organic nature of the development of these networks means that those who take the lead are the leaders; NGO and private sector leaders, who are often not supported by their institutions in network development, are not able to take that lead. Researchers at academic institutions, however, can add research network leadership to their portfolios. When a community leader was asked about this, they expressed gratitude for the time and expertise that university leaders could dedicate to their network and were pleased that the work was continuing despite limited resources of time and money.

Members interviewed from each of the networks identified significant leaders within their networks and highlighted the need to maintain a certain degree of leadership consistency, especially for a time, or as one interviewee put it, "until the network is solidly established.... if you lose your staff or your leadership or champion too soon, or too often I think it affects the stability and the forward movement for sure." It was further noted that "you need to have a champion in leadership but... If you only have one then its vulnerable. If you have a group maybe with a leader but you have a strong group that is keen, then you are going to have a sustainability piece built in as in any organization." This was reiterated by another participant who stated:

If you rely on your executive director and no one else, your executive director leaves and your organization goes belly-up. So, I think it's a network of leaders or supporters that will sustain it over the long term. And grooming people or training people get them into leadership roles. And I don't necessarily mean a full hierarchical thing, but where its team leadership or whatever it takes, it doesn't have to be one person.

Leaders were said to build and nurture relationships and capacity. All network leaders were identified as members of the steering or executive committees and network coordinators. These leaders all have capacity in navigating institutional administration. Several interviewees expressed that network leaders are motivated by strong personal dedication in creating systemic change through their work in the network. The role of the coordinator was highlighted as instrumental in driving the network, both in terms of maintenance and growth. Within each of these networks, the coordinator or project manager, was the only consistently paid position within the networks. Interviewees observed that while the dedication of the leaders keeps the networks alive, the network is not living well without a paid coordinator who pulls the pieces of the network together, maintaining internal and external communications, convening and recruiting members, managing accounts, organizing events, and in some cases writing grant applications.

These leaders are also identified as individuals who foster individual and team leadership,

Engaged Scholar Journal: Community-Engaged Research, Teaching, and Learning 
often by creating trust and space for participation and contribution. As one interviewee said, "the leadership can come out of participation." The external and internal connections of network leaders support the development of the network and of the individuals within it, specifically individuals who are keen on participating actively in the network. It was stated, "there are a few people who are playing an active role in different directions and I think if you are willing to lead in a direction then we should support you in that direction...Someone takes on something that they really want to see happen and others support that." Furthermore, "if somebody gets really excited because of their contribution or participation to the network I can see leadership developing out of that. I can see the champion role coming out of that." As such, strengthening both emerging and existing leaders in the networks' fields is an impact of these networks.

\section{Governance}

Each of the networks has a central governance group, made up of an executive and/or steering committee and some form of advisory committee. Formally, the executive committee sets that direction of the network and is part of the wider steering committee and the advisory board? (in some cases with significant community participation) provides guidance and direction around policy and practice. The coordinator is then the point person who puts tools and processes in place. While each of the networks has a formal governance structure, those members who are actively participating in the network drive the networks. As expressed by one interviewee, "most decisions are made by that core group and there's a yearly meeting where others have influence as well. [Decisions] are arrived at quite collaboratively, but the weight is on those who actually do the work." Trust, a shared mission, and the generally small size of these networks allow for this structure to function. One interviewee stated, "inclusiveness and transparency are the ingredients of a successful network." Another noted that what "makes the governance group work here is that they are pretty clear about their shared mission." Challenges related to governance include working within the bureaucracy of the university or other institutional partners; formalizing informal relationships and governance as the network grows and network goals are clearer; generating governance involvement from members outside of institutions where the resources are abundant enough to support that involvement; and keeping the space open enough for creativity, innovation and inclusion while having sufficient structure for fulfilling goals and fluid network processes such as succession planning for leadership and staff.

\section{Conclusion}

Networks are being used to build trust, collaboration, knowledge sharing, capacity and innovation in the face of complex challenges facing communities and nations and the world. Yet evaluating whether these networks are working is challenging because complex problems are influenced by a myriad of factors, can take a long time to change, and evade standard cause and effect models. For these reasons, network evaluations often examine network processes, relationship dynamics, organizational health, outcomes or incremental steps towards achieving 
results. This article builds on the literature of cross-sector and social change networks to provide insight into the evaluation of CUE network outcomes. Though the questions asked in this study were too broad to get a comprehensive sense of CUE network outcomes and related criteria, several key factors were recognized by the participating CUE networks that influence outcomes: access to resources, alignment and planning, communication, bridging and linking, learning, trust and conflict resolution, leadership, and governance and can be measured at the community-level, network-level and organization-level. Some of the key lessons learned, as highlighted by interviewees, were the following:

1. Face-to-face meetings and conferences foster meaningful conversations around network direction, goals and processes;

2. It helps to use theories of change to assess network outcomes and be creative in language to translate those outcomes and processes to the audience's language;

3. Social media and other on-line communications tools provide metrics that are useful for understanding a network's reach;

4. The network is a space for learning from individual, organizational and collective processes and outputs and difference strengthens the network and the individuals within it;

5. Flexibility and adaptability to external influences and internal changes maintain and grow the network;

6. When core funding is lacking, it is important to think outside of the box in terms of network structures and activities;

7. The network is only as strong as the individuals that move it forward and the strategic plan that they have collaboratively developed;

8. It is difficult to maintain and develop a network without at least one paid coordinator position;

9. Working groups, with significant autonomy, are key to an active network; and

10. Without succession planning (which requires significant leadership and relationship building) the network will not be sustainable.

It is important for networks to assess and acknowledge their role in resulting outcomes, to better understand how these networks' efforts are manifesting change. To do so requires further development and application of indicators or criteria. Many of these criteria relate to a network's connectivity (membership and structure) and its health (resources, infrastructure, and advantage) (Network Evaluation Guide, 2014). Each network has unique forms, functions and processes and is at an evolutionary stage of its development (Plastrik, 2015). Thus, unique criteria for assessing internal (individual and collective) and external outcomes are required. Furthermore, there is a growing body of the benefits of CUE to society that will likely prove extremely valuable for CUE network assessment, criteria that can be used to evaluate both positive and negative network outcomes as there is much to be learned beyond our study.

While our study does not attempt to provide a complete picture of all the outcomes (and challenges) of CUE networks, our findings reinforce the important role they play in bringing 
diverse groups, in this case civil society and higher education, together for opportunities to co-create knowledge. These particular community-based networks, as compared to other professional networks, operate in collaborative ways and help to amplify and strengthen the growing movement towards a knowledge democracy. They do so in ways that value community knowledge, with a shared space for open dialogue, reciprocity and respect - characteristics that are needed in order to collectively solve the contemporary 'wicked' challenges our world faces.

\section{Acknowledgements}

The authors would like to thank the network participants for their valuable time and contribution to this research. This research is supported by the University of Victoria internal funding program.

\section{About the Authors}

Leslie Brown is professor emerita at the School of Social Work, University of Victoria.

Rhianna Nagel is the Community Engaged Learning Coordinator, Faculty of Social Sciences at the University of Victoria.

Jennifer Claire Robinson is currently a Postdoctoral Fellow with the Creative Conciliations research collective through Queen's University and maintains a Research Affiliate position with the Residential and Indian Day School Art Research Program through the Visual Lab at the University of Victoria.

Robyn Spilker is a former Research Assistant with the Institute for Studies and Innovation in Community University Engagement at the University of Victoria. She currently works with the BC Government as a Senior Ministerial Assistant to the Minister of Finance.

Crystal Tremblay (corresponding author) is an Assistant Professor in the Department of Geography and Special Advisor on Community Engaged Scholarship at the University of Victoria. She is also a research coordinator with the UNESCO Chair in Community-based Research in Social Responsibility in Higher Education. Email: crystalt@uvic.ca 


\section{References}

Anderson, Alistair R., Sarah Drakopoulou Dodd, and Sarah Jack.( 2010). Network practices and entrepreneurial growth. Scandinavian Journal of Management, 2, 121-133.

BC Partners for Social Impact. (2014). History. Retrieved from www.hubcapbc.ca.

Bryson, J.M., Crosby, B.C., \& Stone, M.M. (2006). The design and implementation of cross sector collaborations: Propositions from the literature. Public Administration Review, Special Edition, 44-55.

Community-Based Research Canada. (2015). Who We Are. Retrieved from https:// communityresearchcanada.ca/who-we-are/.

Cuthill, Michael. (2012.) A “Civic Mission” for the university: Engaged scholarship and communitybased participatory research. In L. McIlrath et al. (eds.), Higher education and civic engagement. Comparative perspectives. Basingstoke: Palgrave Macmillan.

Escrigas, C., Granados Sanchez, J., Hall, B. L., Tandon, R., Puig, G. and Forns, M., (Eds.). (2014). Higher education in the world 5. Knowledge, engagement and higher education: Contributing to social change. Basingstoke: Palgrave Macmillan.

Foster-Fishman, P., Berkowitz, S., Lounsbury, D., Jacobson, S., \& Allen, N. (2001). Building collaborative capacity in community coalitions: A review and integrative framework. American Journal of Community Psychology, 29(2), 241-261.

Goldsmith, S., \& Eggers, W. (2004). Governing by networks: The new shape of the public sector. Washington: Brookings Institution Press.

Greater Victoria Coalition to End Homelessness. (2014). About Us. Retrieved from victoriahomelessness.ca.

Hall, B. L., Jackson, E. T., Tandon, R., Fontan, J., \& Lall, N. (2013). Knowledge, democracy and action: Community-university research partnerships in perspective. Manchester: Manchester University Press.

Hall, B., Tandon, R., \& Tremblay. C. (2015). Strengthening community university research partnerships: Global perspectives. University of Victoria Press: Victoria, Canada.

Head, Brian W. Assessing network-based collaborations: effectiveness for whom? (2008). Public Management Review, 6, 733-749.

Indigenous Child Well-being Research Network. (2013). Honouring indigenous knowledge and practice.

MacPherson, I. \& Toye, M. (2011). Why staying the course is important: Reflecting on the community-university relationships associated with the Canadian Social Economy Research Partnerships, 2005-2011. In P.V. Hall and I. MacPherson (Eds.), Community-University Research Partnerships: Reflections on the Canadian Social Economy Experience. Victoria: University of Victoria.

Malinsky, E., and C. Lubelsky. 2014. Network evaluation: Cultivating healthy networks for social change. Toronto, ON: Centre for Social Innovation.

Network Evaluation Guide (2014). Framing paper: The state of network evaluation. Network Impact and Center for Evaluation Innovation. Retrieved from networkimpact.org.

Pacific Housing Research Network. (n.d.). About. Retrieved January 24, 2017.

Plastrik, P., \& Taylor, M. (2006). Net gains: A bandbook for network builders seeking social change. Boston: Network Impact.

Popp, J., MacKean, G., Casebeer, A., Milward, H. B., \& Lindstrom, R. (2013). Inter-organizational networks: A critical review of literature to inform practice. Royal Roads University.

Engaged Scholar Journal: Community-Engaged Research, Teaching, and Learning 
Provan, K. G., \& Milward, H. B. (2001). Do networks really work: A framework for evaluating publicsector organizational networks. Public Administration Review, 61, 414-423.

Provan, K.G, Veazie, M.A., Staten, L.K., \& Teufel-Shone, N. (2005). The use of network analysis to strengthen community partnerships. Public Administration Review, 65(5): 603-613.

Provan, K. G., \& Kenis, P. (2008). Modes of networked governance: Structure, management and effectiveness. Journal of Public Administration Research and Theory, 18(2), 229-252.

Tandon, R., Wafa, S., Clover, D., \& Hall, B. (2016). Knowledge democracy and excellence in engagement. Institute of Development Studies Bulletin 47(6), 19-35.

Taylor, M., Whatley, A. \& Coffman, J. (2015). Network Evaluation in Practice: Approaches and Applications. The Foundation Review, 7(2): 22-37.

Tremblay, C. Lepore, W., Singh, W. (2017). Mutual learning and empowering support: networks and balance between local and global demands. In $6^{\text {th }}$ Word report on higher education. Global University for Innovation (GUNi): Barcelona, Spain.

Turrini, A., Cristofoli, D., Frosini, F., \& Nasi, G. (2010). Networking literature about determinants of network effectiveness. Public Administration, 88(2), 528-550.

Vilalta, J.M., Betts, B., \& Gmelch, N. (2017). University and Social Networks: from Theory to Action. In $\sigma^{\text {th }}$ Word Report on Higher Education. Global University for Innovation (GUNi): Barcelona, Spain.

Zornes, D., Ferkins., L \& Piggot-Irvine, E. (2015). Action research networks: role and purpose in the evaluation of research outcomes and impacts. Educational Action Research, 24(1), 97-114. 